\title{
Polarização plasmônica de superfície em nanopartículas de ouro
}

\author{
Prado, A. R. ${ }^{1,3}$; Oliveira, J. P.2; Keijok, W. J.2; Nogueira, B. V.²; Guimarães, M. C. C.2; \\ Frizera Neto, A. ${ }^{1 ;}$ Pontes, M. J. ${ }^{1}$; Ribeiro, M. R. N. ${ }^{1}$ \\ 1 Programa de Pós-Graduação em Engenharia Elétrica, Laboratório de Telecomunicações - Labtel, Universidade \\ Federal do Espírito Santo, Vitória, ES, Brasil \\ 2 Laboratório de Ultraestrutura Celular - LUCCAR, CCS, Universidade Federal do Espírito Santo, Vitória, ES, Brasil \\ 3 Instituto Federal do Espírito Santo, Serra, ES, Brasil
}

\begin{abstract}
Resumo
Atualmente a Ressonância de Plasmon de Superfície (SPR) vem proporcionando resultados significativos nas áreas de sensores e efeito fotônico. Um caso particular de SPR é a Ressonância de Plasmon de Superfície Localizada, porém ao invés de ocorrer sobre um filme metálico fino manifesta-se em NPAu, gerando assim um efeito localizado que é entendido como uma oscilação concorrente entre os elétrons livres no metal. Desse modo, a comunicação e transmissão de energia de uma nanopartícula para outra ocorre de forma mais eficiente quando maior for à interação de dipolo desses sistemas. Portanto, a adição de um componente que promova o aumento da interação das nanopartículas por dipolo gera elevação na absorbância desse sistema. Nesse trabalho foi explorado a interação que ocorrer entre NPAu e íons de sulfeto. Devido à alta capacidade de interação entre o enxofre e o ouro, as NPAu tornam-se mais coesas melhorando assim suas interações no sistema e, por consequência, aumentando a interação energética entre as nanopartículas. Tal comportamento apresenta características interessantes com relação a aplicação em sensores e dispositivos tecnológicos.
\end{abstract}

Keywords (Palavras chaves): plasmon, nanopartícula de ouro, sensores.

\section{Introdução}

O fenômeno estudado nesse trabalho pode ser observado de forma semelhante em nanopartículas de metais ouro, prata, cobre ou suas associações, havendo entre eles forte diferença com relação à resposta óptica gerada pela excitação de plasmon. Devido à facilidade de síntese e estabilidade, além da grande quantidade de trabalhos na literatura explorando as propriedades do ouro nessas aplicações, este material foi o metal explorado nesse estudo. Outros fatores que influenciam na ressonância são o tamanho, a forma e o meio dielétrico onde as nanopartículas estão inseridas. É interessante destacar que mudanças sensíveis no meio promovem significativas alterações na ressonância dessas estruturas, sendo esse um interessante mecanismo a ser usado como sensor [1].

Em situações onde as NPAu encontram-se livres e polarizadas é observado a Polarização por Plasmon de
Superfície (PPS), que ocorre devido o acoplamento de modos eletromagnética e de cargas livres sobre uma superfície metálica, formando assim dipolos nas duas superfícies de contato. A interação entre cargas livres coletivas sobre uma superfície de metal e os campos eletromagnéticos gera também um o campo evanescente que se propaga ao longo da superfície das nanopartículas [1].

Esse trabalho busca entender o efeito de polarização por plasmon em nanopartículas, pois consiste em um fenômeno com grande potencial para aplicação na construção de sensores.

\section{Materiais e Métodos}

$\mathrm{O}$ ácido tetracloroáurico $\left(\mathrm{HAuCl}_{4} \cdot \mathrm{nH}_{2} \mathrm{O}\right.$, Merk) foi usado como precursor das nanopartículas de ouro e o dihidrato de citrato trissódico $\left(\mathrm{Na}_{3} \mathrm{C}_{6} \mathrm{H}_{5} \mathrm{O}_{7} \cdot 2 \mathrm{H}_{2} \mathrm{O}\right.$, Merk) foi usado como agente redutor. Todas as vidrarias $\mathrm{e}$ equipamentos foram higienizadas com uma solução de 
água régia $\left(\mathrm{HCl}: \mathrm{HNO}_{3}\right.$ / 3:1) e lavadas com água deionizada.

Para preparar as NPAu pelo método da redução com citrato, o citrato trissódico foi adicionado à solução precursora de ouro em ebulição [2]. Em seguida a solução foi misturada na mesma temperatura até mudança de coloração para vermelho, e mantido em ebulição durante diferentes intervalos de tempo. As concentrações usados foram de $2,5.10^{-4} \mathrm{M}$ para 0 precursor de ouro $\left(\mathrm{HAuCl}_{4}\right)$ e $3,0.10^{-4} \mathrm{M}$ do agente redutor $\left(\mathrm{Na}_{3} \mathrm{C}_{6} \mathrm{H}_{5} \mathrm{O}_{7}\right)$, sendo 15 minutos o tempo de síntese usado. Para verificar o efeito de polarização plasmônica foi usada uma solução de sulfeto de sódio (Na2S) na concentração de 0,1 M.

Para caracterização da amostra obtida foi um espectrofotometria de UV-Vis (FEMTO $800 \mathrm{XI}$ ) e o tamanho e morfologia das nanopartículas foram examinadas por microscopia eletrônica de transmissão (JEOL, JEM1400).

\section{Resultados e Discussão}

Nesse trabalho foi sintetizado nanopartículas com morfologia esférica, como tais sistemas não são esferas perfeitas a própria irregularidade superficial contribui para a formação de acúmulos de carga diferenciada ao logo de toda NPAu. A seguir é apresentada uma imagem em MET da amostra sintetizada antes da manifestação do efeito de polarização.

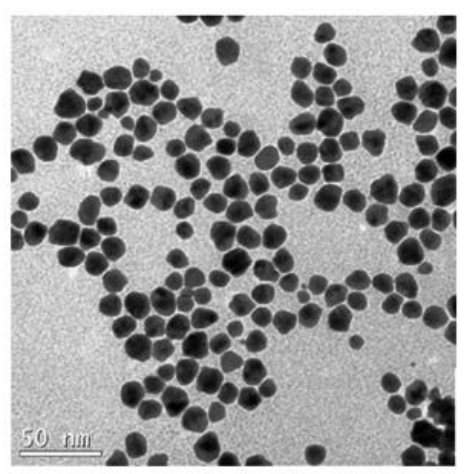

Figura 1: Imagem de micrografia eletrônica de transmissão (MET) das nanopartículas de ouro antes da adição de sulfeto.

A figura a seguir mostra o efeito de aglutinação provocado pela adição de sulfeto ao sistema, para isso aforam adicionados $0,5 \mathrm{~mL}$ de uma solução previamente preparada. Tal efeito ocorrer devido a forte força de ligação entre o ouro e os íons de enxofre. Sendo esse feito já comprovado na literatura. Outra característica interessante é a carga presente no íon fato que motiva a conexão do mesmo a mais de uma NPAu simultaneamente, favorecendo o processo de polarização e comunicação energética entre as nanopartículas [3]. A figura a seguir mostra o efeito de aglutinação e comunicação energética entre as NPAu.

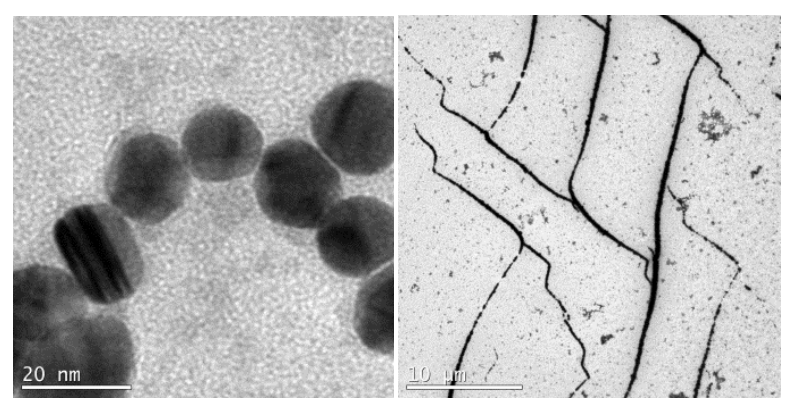

Figura 2: Imagem de micrografia eletrônica de transmissão (MET) das nanopartículas de ouro conectadas devido o efeito de Polarização de Plasmon de Superfície.

\section{Conclusão}

Esse trabalho mostra uma forma simples de sintetizar nanopartículas de ouro e o comportamento elétrico desses sistemas em ambiente onde é privilegiada a Polarização por Plasmon de Superfície. Tal fenômeno foi provocado pela adição de íons de sulfeto, que apresentam grande interação química com as NPAu. O entendimento desse fenômeno é de grande importância para a construção de dispositivos tecnológicos como sensores e células solares.

\section{Agradecimentos}

Esse trabalho teve superte da Petrobras S.A.. Ministério da Ciência e Tecnologia (CNPq 483036/2011-0 Grant), o Ministério da Educação (MECPROEXT Grant 04/2011) e do Ministério da Ciência e Tecnologia (MCTI / FINEP / CT-INFRA PROINFRA conceder 01/2006). Fundação de Amparo à Pesquisa do Espírito Santo (FAPES concessão 018/2012).

\section{Referências}

[1] Tinguely, J., C., Sow, I., Leiner, C., Grand, J., Hohenau, A., Felidj, N., Aubard, J., Krenn, J. R. BioNanoScience , v 1, p. 128-135, 2011.

[2] Zhao, P., Li, N., Astruc, D. Coordination Chemistry Reviews, v. 257, p. 638-665, 2013.

[3] Huang Y.; Kim D. H. Nanoscale. Res. Letters, v. 3, p. 3228-23, 2011. 